\title{
Influência do Tipo de Agente de Partição da Borracha Nitrílica na Obtenção de Blendas PVC/NBR
}

\author{
Fábio R. Passador, Luiz A. Pessan \\ Departamento de Engenharia de Materiais, UFSCar \\ Antonio Rodolfo Jr. \\ Braskem S/A
}

\begin{abstract}
Resumo: Borrachas nitrílicas para utilização em misturas com PVC são fornecidas em forma de pó, que são recobertas com um agente de partição para evitar compactação do produto no transporte e armazenamento, além de garantir alta fluidez e livre escoamento. Neste trabalho, buscou-se estudar a influência do tipo de agente de partição da borracha nitrílica (resina de $\mathrm{PVC}$ e $\mathrm{CaCO}_{3}$ ) na obtenção de blendas $\mathrm{PVC/NBR}$. As propriedades mecânicas das blendas foram avaliadas por ensaios de tração, rasgo e dureza. As blendas com NBR com agente de partição de PVC apresentaram maior tensão na ruptura e módulo elástico que as blendas em que utilizaram NBR com agente de partição de $\mathrm{CaCO}_{3}$. A morfologia foi avaliada por microscopia eletrônica de varredura sendo bastante afetada pelo tipo de agente de partição.
\end{abstract}

Palavras-chave: Blenda PVC/NBR, poli(cloreto de vinila), borracha nitrílica, agente de partição.

\section{Influence of the Partitioning Agent on the Preparation of PVC/NBR Blends}

Abstract: Nitrile rubbers used in mixture with PVC resin are supplied in powder. This kind of nitrile rubber has a partitioning agent to avoid agglomeration in the particles during the transport and storage. In this study, the influence of the partitioning agent on the preparation of PVC/NBR blends was investigated. The mechanical properties of the blends were evaluated by tensile properties, tear strength and hardness. The PVC/NBR blends with partitioning agent of PVC showed an increase in the tensile stress and Young's modulus compared to the PVC/NBR blends with partitioning agent of $\mathrm{CaCO}_{3}$. The morphology of the blends examined by scanning electron microscopy demonstrated the influence of the partitioning agent.

Keywords: PVC/NBR blends, poly (vinyl chloride), nitrile rubber, partitioning agent.

\section{Introdução}

Dentre os inúmeros tipos e variedades de borrachas existentes no mercado brasileiro, a borracha nitrílica destaca-se como a mais utilizada nos diversos setores da atividade industrial, em especial em misturas com PVC. Blendas PVC/NBR são de grande interesse tecnológico devido à obtenção de materiais com grande aplicabilidade, com custo e desempenho diferenciado. A grande versatilidade do PVC e a possibilidade de incorporação de aditivos, aliadas às propriedades intrínsecas da borracha nitrílica, como elevada resistência a óleos e solventes, gera produtos com ampla gama de aplicações. A incorporação da borracha nitrílica promove melhoria na resistência ao ozônio, envelhecimento e resistência química do PVC, enquanto que o PVC, por sua vez, melhora as propriedades de abrasão, rasgamento e tração da $\mathrm{NBR}^{[1-3]}$.

Borrachas nitrílicas para incorporação em compostos de PVC são fornecidas em forma de pó, ao qual são recobertas com um agente de partição (resina de PVC, carbonato de cálcio ou sílica) para evitar compactação do produto no transporte e armazenamento, além de garantir alta fluidez e livre escoamento. As borrachas nitrílicas em pó conferem melhor qualidade de mistura devido a sua forma física, que elimina a etapa de mastigação, tanto em misturadores fechados quanto em misturadores abertos. Há indícios de que o tipo de agente de partição incorporado à borracha nitrílica facilita o processamento e auxilia no aumento na resistência à abrasão, além de diminuir a resistência à compressã $0^{[4,5]}$.

Para melhor compreensão da influência do agente de partição no processamento e nas propriedades finais das blendas PVC/NBR foi necessário manter o mesmo teor de acrilonitrila da NBR. A variação do teor de acrilonitrila na composição de blendas PVC/NBR tem sido objeto de estudo de muitos pesquisadores e, de maneira geral, o desempenho mecânico das blendas aumenta com o teor de acrilonitrila na NBR até um teor ótimo a partir da qual se observa o comprometimento das propriedades mecânicas, gerando blendas com morfologia de fases aglomeradas e heterogêneas ${ }^{[6-11]}$.

A proposta desse trabalho foi estudar a influência do tipo de agente de partição da NBR (resina de PVC e carbonato de cálcio) no processamento, nas propriedades térmi-

Autor para correspondência: Fábio R. Passador, Departamento de Engenharia de Materiais, UFSCar, Caixa Postal 676, CEP: 13560-970, São Carlos, SP, Brasil. E-mail: fabiopassador@gmail.com 
cas, mecânicas e na morfologia de blendas PVC/NBR nas proporções de 90/10, 80/20 e 70/30\% em massa.

\section{Experimental}

\section{Materiais}

Foram utilizados neste estudo o poli (cloreto de vinila) (PVC) com valor $\mathrm{K}=71 \pm 1$, cedido pela Braskem S.A.; o dioctil ftalato (DOP), fornecido pela Scandiflex e o estabilizante térmico a base de $\mathrm{Ba} / \mathrm{Zn}$ fornecido pela Inbra Indústrias Químicas Ltda.

Foram utilizadas duas borrachas nitrílicas com diferentes agentes de partição, ambas cedidas pela Petroflex Indústria e Comércio S.A., Thoran NP-3351 C (denominada NBR PC) e Thoran NP-3351 P (denominada NBR PP), sendo as propriedades características apresentadas na Tabela 1.

\section{Preparação do composto de PVC}

O composto de PVC foi obtido pela adição de 100 pcr de resina de PVC, 60 pcr de DOP e 3 pcr de estabilizante térmico em um misturador Mecanoplast ML-9, a $120^{\circ} \mathrm{C}$.

\section{Reometria capilar}

Os parâmetros reológicos, como a viscosidade e a razão de viscosidades a altas taxas de cisalhamento, foram determinados utilizando-se um rêometro capilar, marca Instron, modelo 4467, com um capilar de comprimento (1) de $30,73 \mathrm{~mm}$ e diâmetro (d) de 1,52 mm e, portanto, razão 1/d igual a 20 . $\mathrm{O}$ ensaio foi realizado para o composto de PVC e para as borrachas nitrílicas na temperatura de $160^{\circ} \mathrm{C}$ e as faixas de cisalhamento exploradas foram entre 5 e $100 \mathrm{~s}^{-1}$.

\section{Preparação das blendas}

As blendas PVC/NBR nas proporções de 90/10; 80/20; 70/30\% em massa foram processadas em reômetro de torque Haake, modelo Rheomix 600 à $160^{\circ} \mathrm{C}$, com rotação de $60 \mathrm{rpm}$ e tempo de mistura de 5 minutos.

Tabela 1. Propriedades típicas dos elastômeros utilizados.

\begin{tabular}{cccc}
\hline Propriedades & Método & NBR PC & NBR PP \\
\hline Característica & - & $\begin{array}{c}\text { Não } \\
\text { vulcanizada }\end{array}$ & $\begin{array}{c}\text { Parcialmente } \\
\text { vulcanizada }\end{array}$ \\
\hline Teor de AN (\%) & ITL & $33,0 \pm 2,0$ & $32,5 \pm 1,5$ \\
& 10.007 & & \\
\hline $\begin{array}{c}\text { Viscosidade } \\
\text { mooney }\end{array}$ & ASTM & $48,0 \pm 5,0$ & $50,0 \pm 5,0$ \\
D-1646 & & \\
@ $\left.100{ }^{\circ} \mathrm{C}\right)$ & & & \\
\hline $\begin{array}{c}\text { Tipo de agente de } \\
\text { partição }\end{array}$ & - & $\mathrm{CaCO}_{3}$ & PVC \\
\hline $\begin{array}{c}\text { Teor de agente de } \\
\text { partição }(\%)\end{array}$ & $\begin{array}{c}\text { ITL } \\
10.390\end{array}$ & $10,0 \pm 2,0$ & $12,5 \pm 2,5$ \\
\hline
\end{tabular}

\section{Comportamento térmico}

O comportamento térmico das blendas foi observado por Calorimetria Exploratória Diferencial (DSC). Para as análises, utilizou-se o aparelho da TA QS100, sendo a faixa de temperatura estudada de $-50{ }^{\circ} \mathrm{C}$ até $125^{\circ} \mathrm{C}$, com taxa de aquecimento de $20^{\circ} \mathrm{C} / \mathrm{min}$.

\section{Ensaios mecânicos}

A caracterização mecânica foi realizada a partir dos ensaios de tração, resistência ao rasgo e dureza das blendas.

Os ensaios de tração foram realizados numa máquina universal de ensaios MTS modelo Aliance RT/5 seguindo a norma ASTM D-638, em corpos de prova do tipo IV com formato de "gravata". Foi utilizado uma célula de carga de $5 \mathrm{KN}$, velocidade da travessa de $500 \mathrm{~mm} / \mathrm{min}$, com a utilização de extensômetro.

Os ensaios de resistência ao rasgo foram realizados numa máquina universal de ensaios MTS modelo Aliance RT/5 seguindo a norma ASTM D-1004, com velocidade da travessa de $51 \mathrm{~mm} / \mathrm{min}$.

Para o ensaio de dureza Shore A foi utilizado um durômetro com relógio digital da Bareiss, segundo a norma ASTM D-2240. Foram preparados corpos de prova cilíndricos de $6,0 \pm 0,2 \mathrm{~mm}$ de espessura e 5,0 $\pm 0,2 \mathrm{~cm}$ de diâmetro. Foram realizadas cinco medidas em cada amostra.

\section{Caracterização morfológica}

A morfologia foi analisada utilizando um microscópio eletrônico de varredura (MEV) da marca Philips, modelo XL30 FEG. A superfície das amostras foi atacada quimicamente por uma solução de $100 \mathrm{~mL}$ de $\mathrm{H}_{2} \mathrm{SO}_{4}, 30 \mathrm{~mL}$ de $\mathrm{H}_{3} \mathrm{PO}_{4}, 30 \mathrm{~mL}$ de $\mathrm{H}_{2} \mathrm{O}$ e $3 \mathrm{~g}$ de $\mathrm{K}_{2} \mathrm{Cr}_{2} \mathrm{O}_{7}$ por 5 minutos a $30{ }^{\circ} \mathrm{C}$ para remover a fase NBR e recobertas com ouro para a observação em microscópio.

\section{Resultados e Discussão}

\section{Avaliação dos parâmetros reológicos}

A Figura 1 apresenta as curvas de viscosidade em função da taxa de cisalhamento para o composto de PVC, NBR PC e NBR PP, obtidas por reometria capilar a $160{ }^{\circ} \mathrm{C}$, em uma faixa de taxa de cisalhamento entre 5 e $100 \mathrm{~s}^{-1}$.

Tanto o composto de PVC quanto as borrachas nitrílicas apresentaram comportamento pseudoplástico, onde a viscosidade diminui com o aumento da taxa de cisalhamento e possuem comportamento característico ao de fluidos que seguem o modelo de lei das potências $(\tau=\eta \cdot \dot{\gamma})$, onde $\tau$ é a tensão, $\eta$ é a viscosidade e $\dot{\gamma}$ é a taxa de cisalhamento. Neste modelo a viscosidade pode ser representada pela relação $\eta=m \cdot \dot{\gamma}^{\mathrm{n}-1}$, onde $\mathrm{m}$ é a consistência e $\mathrm{n}$ é o índice de pseudoplasticidade ${ }^{[12,13]}$.

Através da microrreologia é possível correlacionar as características reológicas da mistura com a morfologia final da blenda $^{[2,14]}$. Taylor citado por Utraki ${ }^{[15]}$ estendeu as pesquisas 


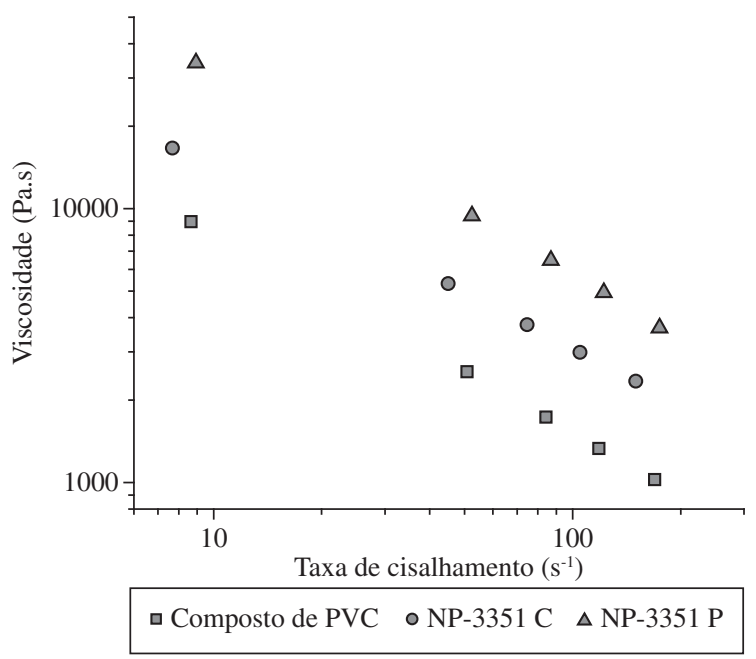

Figura 1. Curvas de viscosidade em função da taxa de cisalhamento para o composto de PVC, NBR PC e NBR PP.

de Einstein sobre a deformação e quebra da gota de líquidos em meios líquidos. Sendo que uma forma de compreender o comportamento sob fluxo de blendas poliméricas é através da dispersão de uma gota de um líquido Newtoniano em outro líquido Newtoniano, por exemplo, gotas de óleo em água, sujeitas a campos deformacionais bem definidos. Taylor observou que o comportamento das gotas é influenciado por dois fatores: razão de viscosidade e número de capilar.

A Figura 2 apresenta a razão de viscosidades, a $160^{\circ} \mathrm{C}$, entre NBR PC e o composto de PVC e entre NBR PP e o composto de PVC em função da taxa de cisalhamento.

De acordo com a teoria de Taylor ${ }^{[15]}$, para um fluido newtoniano disperso em outro fluido newtoniano sob fluxo cisalhante, quando a razão de viscosidades estiver entre 0,7 e 3,7 espera-se que a fase dispersa se alongue em fibrilas, e estas se rompam por mecanismos de instabilidade capilar.

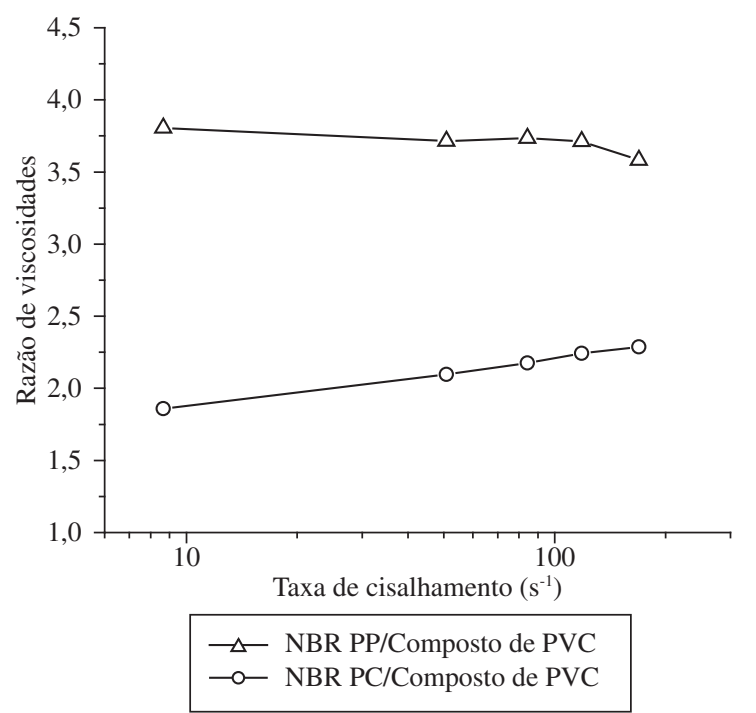

Figura 2. Razão de viscosidades entre NP-3351 C e o composto de PVC e entre NP-3351 P e o composto de PVC em função da taxa de cisalhamento obtida a $160{ }^{\circ} \mathrm{C}$.
Como o processamento realizado para obtenção das blendas foi reometria de torque, há de se considerar também o fluxo elongacional presente, além do fenômeno de coalescência de partículas, situações não abordadas no modelo de Taylor.

Dessa forma, espera-se que a morfologia das blendas PVC/NBR PC fossem compostas por uma fase dispersa tendendo ao formato esférico, com tamanho reduzido e boa dispersão na matriz, já que a razão de viscosidades se encontra dentro do intervalo estimado por Taylor. No entanto, como a razão de viscosidades entre NBR PP e o composto de PVC se apresentou acima do limite teórico de 3,7, espera-se que a morfologia final da blenda PVC/NBR PP seja composta por fase dispersa esférica, porém com maior tamanho de partícula e pior dispersão, devido à grande dificuldade de deformação e quebra da fase dispersa, além da maior possibilidade das partículas coalescerem.

\section{Avaliação da processabilidade das blendas}

A Figura 3 apresenta a variação do torque de equilíbrio com o aumento do teor de NBR das blendas estudadas com diferentes borrachas nitrílicas.

Comparando os resultados obtidos pode-se observar que o aumento no teor de NBR promove aumento no torque de equilíbrio, sendo mais sensível para as blendas com NBR PP. A borracha nitrílica possui maior viscosidade comparada ao PVC (como visto por reometria capilar) e, dessa forma, aumentando-se o teor de NBR ocorreu o aumento na fricção entre as partículas de PVC e NBR ocasionando aumento no torque de equilíbrio. $\mathrm{O}$ agente de partição interfere na viscosidade dos elastômeros, sendo que quanto maior a viscosidade da fase dispersa, maior será o torque de equilíbrio. Dessa forma, observou-se que nas blendas em que se utilizou NBR PP ocorreu aumento mais significativo do torque de equilíbrio com o aumento no teor de NBR, comparado às blendas com NBR PC. O aumento no torque de equilíbrio para as blendas

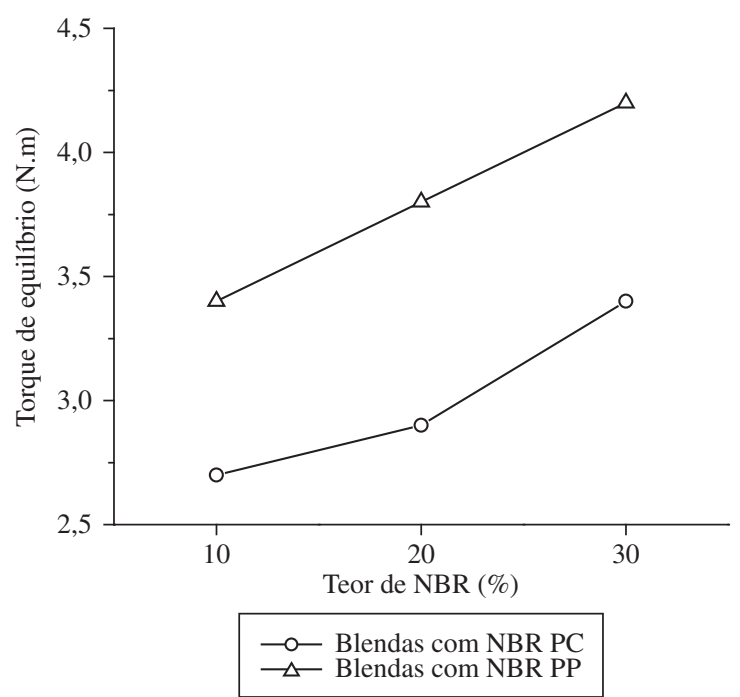

Figura 3. Variação do torque de equilíbrio com o aumento do teor de NBR das blendas. 
com NBR PP também está relacionado com a presença de pequenas quantidades de reticulações deste elastômero.

\section{Análise térmica}

A Figura 4 apresenta os termogramas de DSC do composto de PVC, das borrachas nitrílicas com diferentes tipos de agente de partição e das blendas PVC/NBR nas proporções de 90/10, 80/20 e 70/30\% em massa.

A Tabela 2 apresenta os valores de $\mathrm{T}_{\mathrm{g}}$ dos materiais analisados. As determinações dos valores da $\mathrm{T}_{\mathrm{g}}$ foram feitas a partir da derivação da curva de fluxo de calor em função da temperatura, determinando-se o ponto de inflexão característico desta transição.

A incorporação dos aditivos de processamento na resina de PVC, como o DOP, por exemplo, influencia no comportamento térmico do composto de PVC. O plastificante penetra através dos poros existentes nas partículas da resina de PVC diminuindo a atração intermolecular das cadeias poliméricas e aumentando a mobilidade destas, como consequiência ocorre uma diminuição da rigidez do composto e na temperatura de transição vítrea. Na Figura 4a observou-se a presença de uma transição endotérmica de segunda ordem em $65{ }^{\circ} \mathrm{C}$,

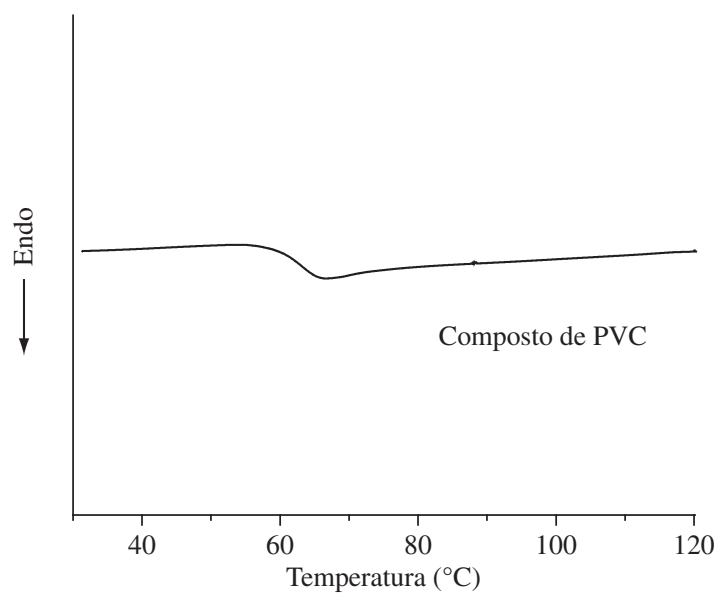

(a)

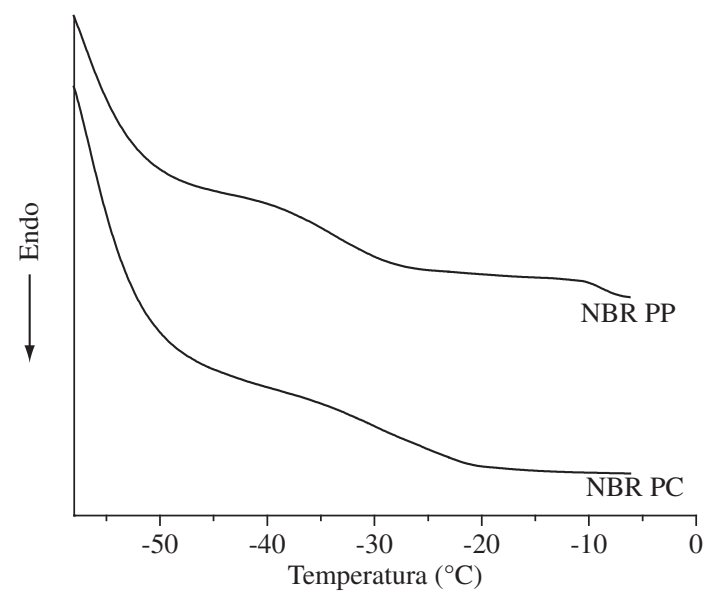

(b)
Tabela 2. Temperaturas de transição vítrea $\left({ }^{\circ} \mathrm{C}\right)$ obtidas por DSC do composto de PVC, da NBR PC, NBR PP e das blendas estudadas.

\begin{tabular}{ccc}
\hline Material & $\mathbf{T}_{\mathrm{g}}$ NBR & $\mathbf{T}_{\mathrm{g}} \mathbf{P V C}$ \\
\hline Composto de PVC & - & $65{ }^{\circ} \mathrm{C}$ \\
NBR PC & $-30{ }^{\circ} \mathrm{C}$ & - \\
NBR PP & $-33{ }^{\circ} \mathrm{C}$ & - \\
PVC/NBR PC (90/10) & $-4{ }^{\circ} \mathrm{C}$ & $63{ }^{\circ} \mathrm{C}$ \\
PVC/NBR PC $(80 / 20)$ & $-1{ }^{\circ} \mathrm{C}$ & $62{ }^{\circ} \mathrm{C}$ \\
PVC/NBR PC $(70 / 30)$ & $3{ }^{\circ} \mathrm{C}$ & $61{ }^{\circ} \mathrm{C}$ \\
PVC/NBR PP $(90 / 10)$ & $4{ }^{\circ} \mathrm{C}$ & $60{ }^{\circ} \mathrm{C}$ \\
PVC/NBR PP $(80 / 20)$ & $5{ }^{\circ} \mathrm{C}$ & $62{ }^{\circ} \mathrm{C}$ \\
PVC/NBR PP $(70 / 30)$ & $5{ }^{\circ} \mathrm{C}$ & $62{ }^{\circ} \mathrm{C}$ \\
\hline
\end{tabular}

correspondente a $\mathrm{T}_{\mathrm{g}}$ do composto de $\mathrm{PVC}$, sendo esse valor inferior ao da resina de PVC $\left(90^{\circ} \mathrm{C}\right)$.

$\mathrm{O}$ estado de mistura do sistema PVC/NBR está diretamente relacionado ao teor de acrilonitrila da borracha nitrílica. Segundo a literatura ${ }^{[10,11,16-18]}$, verifica-se que o grau de miscibilidade aumenta com o teor de acrilonitrila na NBR até um teor ótimo a partir da qual se observa o comprometimento das propriedades mecânicas, gerando blendas com morfologia de fases aglomeradas e heterogêneas. A análise

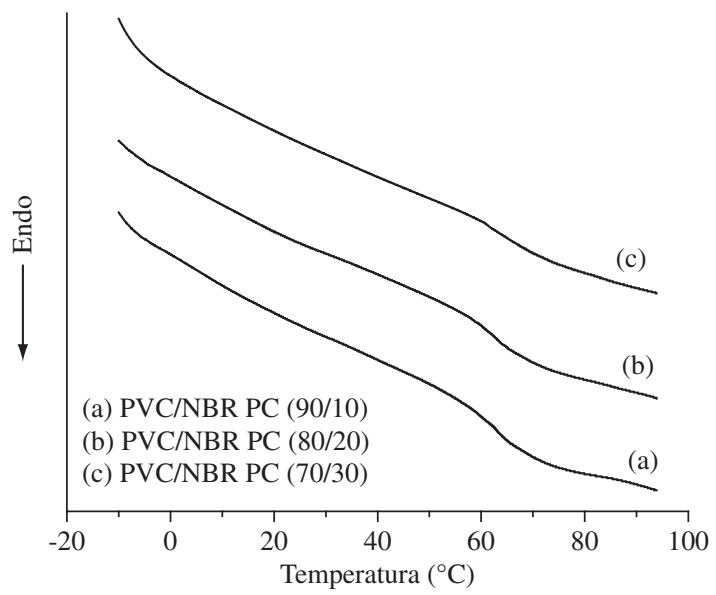

(c)

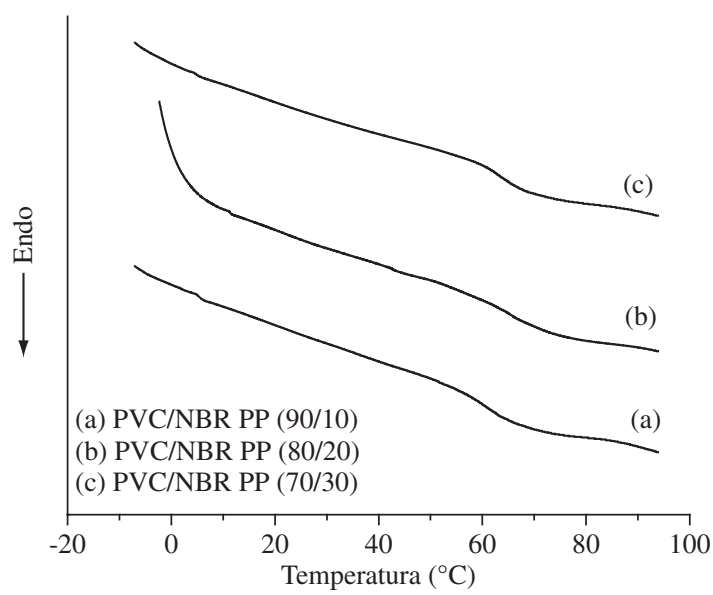

(d)

Figura 4. Termogramas de DSC: a) Composto de PVC; b) NBR PC e NBR PP; c) blendas PVC/NBR PC; e d) blendas PVC/NBR PP. 
do comportamento térmico das blendas sob aquecimento revela a presença de duas transições endotérmicas de segunda ordem, sendo os valores encontrados intermediários entre a $\mathrm{T}_{\mathrm{g}}$ do $\mathrm{PVC}$ e a $\mathrm{T}_{\mathrm{g}}$ da NBR. Em relação à variação dos teores de NBR incorporados no PVC, pode-se observar através da análise térmica que todos os sistemas são imiscíveis, ou seja, houve a formação de mais de uma fase na blenda, notadamente pelo surgimento de dois valores de temperatura de transição vítrea. Observou-se também que houve deslocamentos nos valores da $T_{g}$, tanto do PVC quanto da NBR. Quanto maior o teor de NBR na blenda, mais próximos são os valores de $\mathrm{T}_{\mathrm{g}}$, ou seja, o aumento da quantidade de acrilonitrila na composição da blenda aumenta o grau de interação e/ou miscibilidade parcial. O tipo de agente de partição da borracha nitrílica exerceu pouca influência nos valores das temperaturas de transição vítrea das blendas.

\section{Avaliação das propriedades mecânicas}

O composto de PVC, as borrachas nitrílicas com diferentes tipos de agente de partição e as blendas PVC/NBR foram caracterizadas quanto suas resistências mecânicas através de ensaios de tração, resistência ao rasgo e dureza.

A partir do ensaio de tração foram obtidas informações sobre a tensão na ruptura $\left(\sigma_{\mathrm{r}}\right)$, deformação na ruptura $\left(\varepsilon_{\mathrm{r}}\right)$ e módulo elástico (E) dos sistemas estudados, que estão apresentados na Tabela 3 .

Analisando os resultados de tensão na ruptura observouse que a NBR possui baixa tensão na ruptura, para ambos os tipos de agente de partição, porém NBR PP apresentou valor superior de tensão de ruptura comparado a NBR PC. Variando-se o teor de NBR nas composições das blendas estudadas, observa-se que todas as blendas apresentaram valores superiores de tensão na ruptura comparados à NBR pura. Pode-se observar ainda, que o valor da tensão na ruptura diminui à medida que aumenta o teor de NBR em comparação ao va-

Tabela 3. Tensão na ruptura $\left(\sigma_{\mathrm{r}}\right)$, deformação na ruptura $\left(\varepsilon_{\mathrm{r}}\right)$ e módulo elástico (E) do composto de PVC, das borrachas nitrílicas e das blendas estudadas.

\begin{tabular}{cccc}
\hline Amostra & $\sigma_{\mathrm{r}}(\mathbf{M P a})$ & $\varepsilon_{\mathrm{r}}(\%)$ & $\mathbf{E}(\mathbf{M P a})$ \\
\hline $\begin{array}{c}\text { Composto de } \\
\text { PVC }\end{array}$ & $15,2 \pm 0,2$ & $411,6 \pm 11,6$ & $10,55 \pm 0,16$ \\
NBR PC & $0,4 \pm 0,1$ & $605,8 \pm 24,3$ & $1,44 \pm 0,13$ \\
NBR PP & $0,9 \pm 0,3$ & $594,6 \pm 15,7$ & $1,36 \pm 0,03$ \\
PVC/NBR PC & $10,7 \pm 0,4$ & $406,3 \pm 1,7$ & $6,93 \pm 0,17$ \\
$\quad(90 / 10)$ & & & \\
PVC/NBR PP & $14,7 \pm 0,2$ & $799,1 \pm 19,6$ & $2,61 \pm 0,26$ \\
$\quad(90 / 10)$ & & & \\
PVC/NBR PC & $7,6 \pm 0,1$ & $595,4 \pm 11,8$ & $1,65 \pm 0,05$ \\
$\quad(80 / 20)$ & & & \\
PVC/NBR PP & $12,5 \pm 0,3$ & $382,2 \pm 12,6$ & $6,29 \pm 0,09$ \\
$\quad(80 / 20)$ & & & \\
PVC/NBR PC & $7,7 \pm 0,2$ & $347,3 \pm 4,9$ & $4,51 \pm 0,10$ \\
$\quad(70 / 30)$ & & & \\
PVC/NBR PP & $11,1 \pm 0,3$ & $365,2 \pm 11,5$ & $5,17 \pm 0,13$ \\
$(70 / 30)$ & & & \\
\hline
\end{tabular}

lor do composto de PVC. Blendas PVC/NBR que utilizaram em sua composição NBR particulada com PVC apresentaram valores superiores de tensão na ruptura, fato esperado uma vez que esse tipo de elastômero é caracterizado como pré-vulcanizado, possuindo, desta forma, uma determinada porcentagem de ligações cruzadas o que contribui com um aumento na rigidez da fase NBR na blenda, aumentando a resistência mecânica.

Quanto a deformação na ruptura, pode-se notar que o composto de PVC possui grande deformação na ruptura devido à grande quantidade de plastificante utilizada em sua formulação, que auxilia no aumento da flexibilidade das cadeias poliméricas ${ }^{[4]}$. Não foi verificada uma tendência no comportamento da deformação na ruptura das blendas com o aumento no teor de NBR, porém se considerarmos os resultados de tensão na ruptura observa-se que quanto maior a tensão obtida, menor a deformação das blendas. No caso

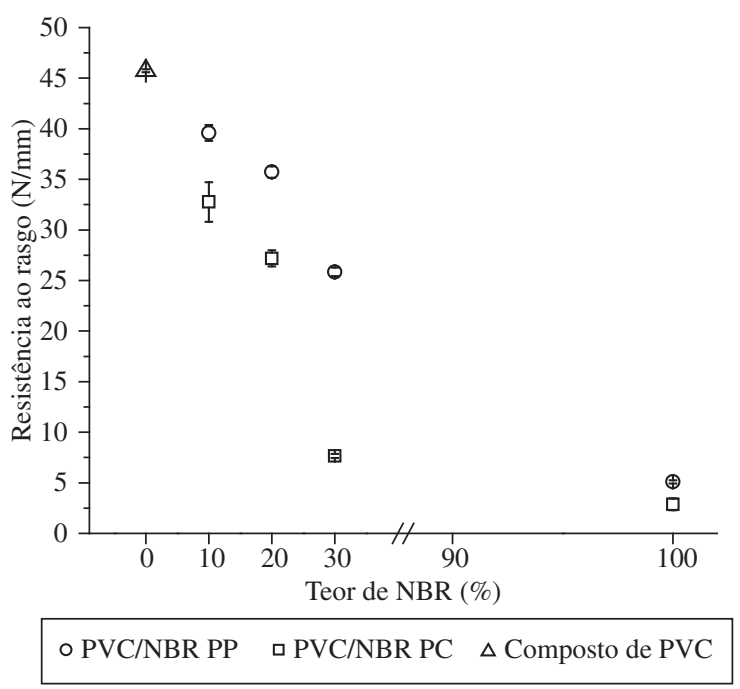

Figura 5. Resistência ao rasgo em função do teor de NBR do composto de PVC, das borrachas nitrílicas e das blendas obtidas com diferentes agentes de partição.

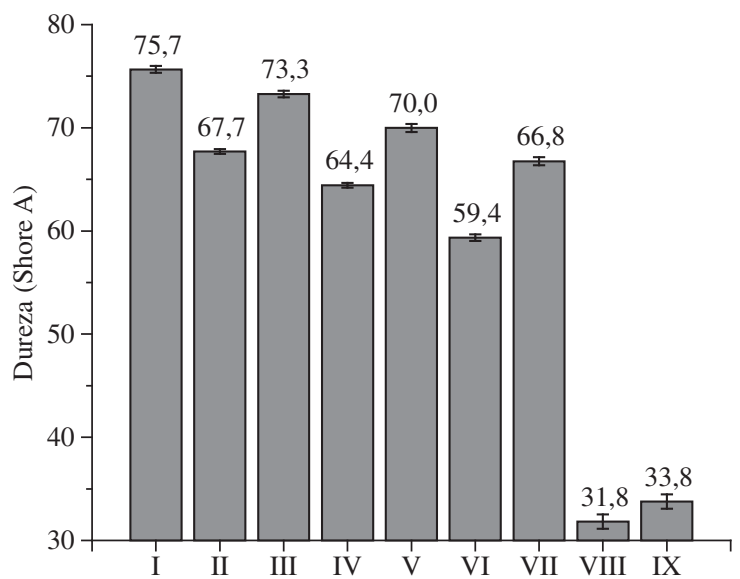

Figura 6. Dureza Shore A: I) Composto de PVC; II) PVC/NBR PC (90/10); III) PVC/NBR PP (90/10); IV) PVC/NBR PC (80/20); V) PVC/NBR PP (80/20); VI) PVC/NBR PC (70/30); VII) PVC/NBR PP (70/30); VIII) NBR PC; e IX) NBR PP. 
da blenda PVC/NBR PC (80/20) observou-se um aumento nos valores de deformação na ruptura que pode estar relacionado à dispersão da fase elastomérica na matriz de PVC, que pode ter auxiliado no mecanismo de deformação desta blenda, sendo obtido valores superiores ao observado para o composto de PVC. Pode-se observar que blendas PVC/ NBR PP possui menor deformação na ruptura já que este elastômero é pré-vulcanizado e suas partículas são mais rígidas.

Elastômeros possuem módulos de elasticidade relativamente baixos ${ }^{[19,20]}$, somo observado para NBR PC E NBR PP. Aumentando-se o teor de NBR na composição das blendas

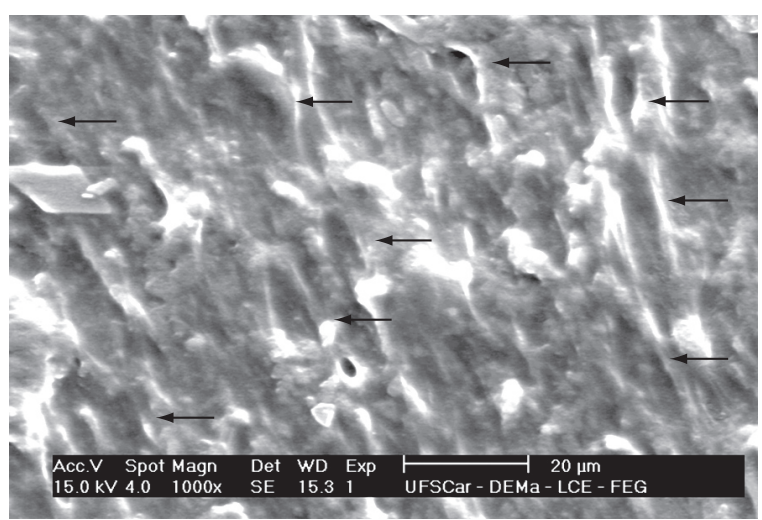

(a)

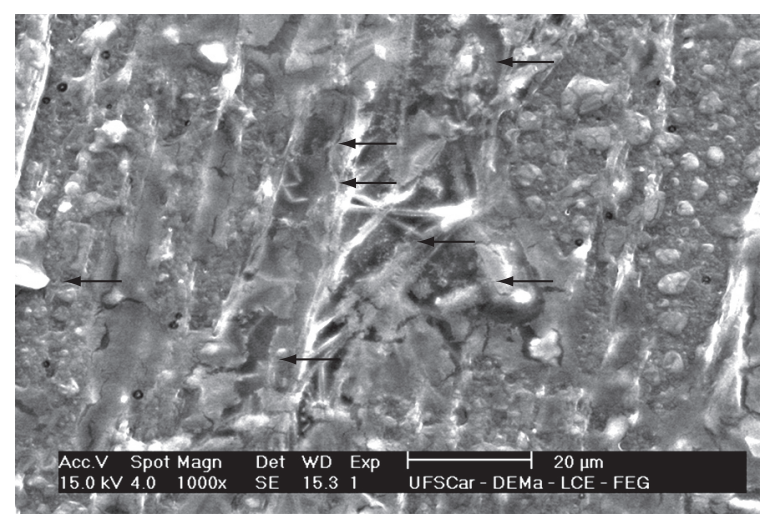

(b)

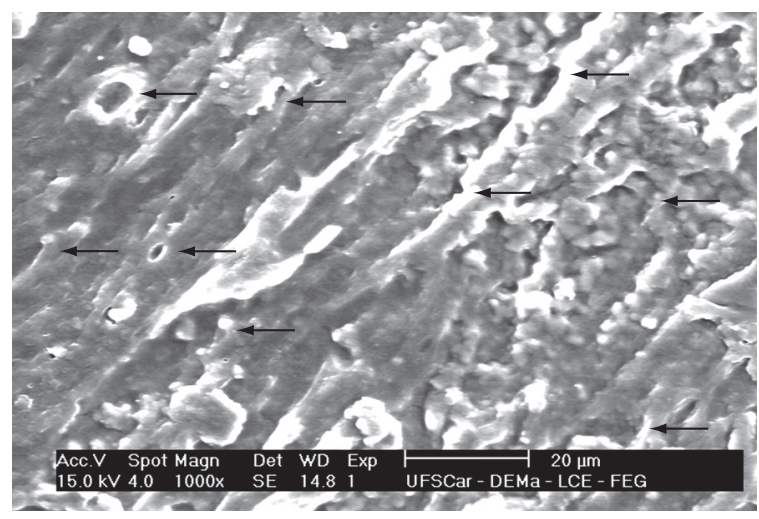

(c) verifica-se a diminuição do módulo elástico em comparação com o valor obtido para o composto de PVC. A blenda PVC/NBR PC (80/20) apresentou valor de módulo elástico menor que a blenda PVC/NBR PC (70/30), este comportamento pode estar relacionado à dispersão da fase elastomérica na blenda. Quanto à influência do tipo de agente de partição da NBR pode-se verificar que os maiores valores de módulo elástico são encontrados para as blendas que utilizaram NBR particulada com PVC em suas composições.

A resistência ao rasgo é a medida da energia necessária para rasgar o corpo de prova, que inclui a energia requerida para distender totalmente o elastômero e depende parcialmen-

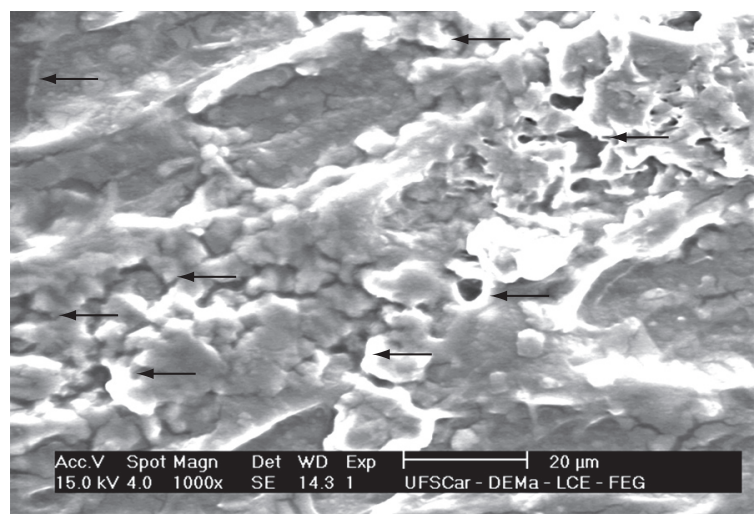

(d)

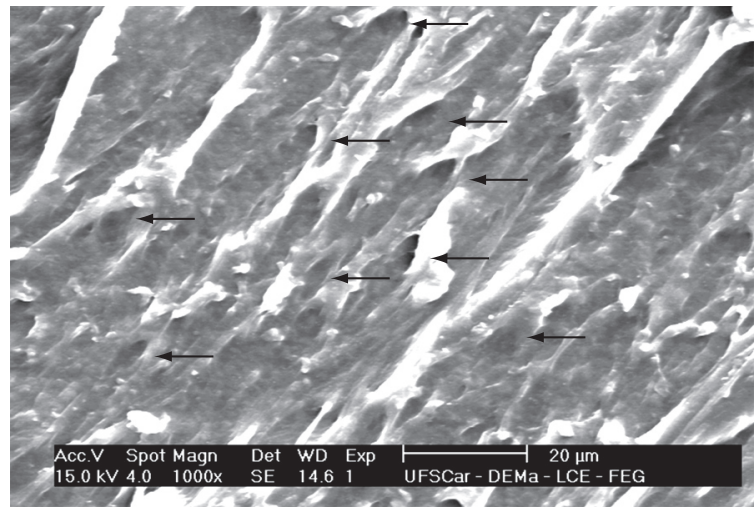

(e)

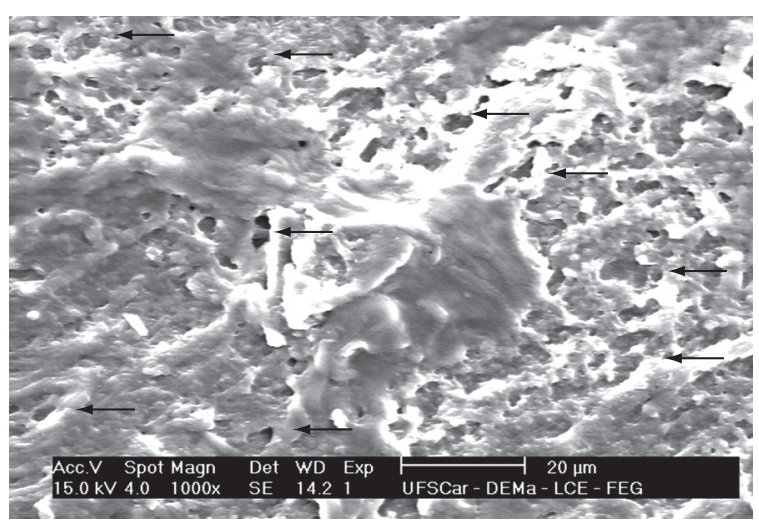

(f)

Figura 7. Micrografias de MEV das blendas a) PVC/NBR PC (90/10); b) PVC/NBR PC (80/20); c) PVC/NBR PC (70/30); d) PVC/NBR PP (90/10); e) PVC/NBR PP (80/20); e f) PVC/NBR PP (70/30). Aumento de 1000x. 
te das propriedades viscoelásticas do material. A Figura 5 apresenta os resultados do ensaio de resistência ao rasgo do composto de PVC, das borrachas nitrílicas e das blendas obtidas com diferentes agentes de partição.

O aumento do teor de NBR diminui a resistência ao rasgo nas blendas devido à baixa resistência ao rasgo da NBR pura, quando comparado ao valor obtido para o composto de PVC. Comparando os valores de resistência ao rasgo em função do tipo de agente de partição da NBR, notou-se que as blendas que utilizaram NBR PP apresentaram resultados de resistência ao rasgo superior àquelas em que foi utilizado NBR PC. Para 30\% em massa de NBR o comportamento observado da blenda particulada com $\mathrm{CaCO}_{3}$ pode estar relacionado à dispersão da fase NBR na matriz de PVC, uma vez que ensaios de reometria capilar mostraram através da razão de viscosidades entre NBR PC e o composto de PVC, que as partículas de NBR devem estar bem dispersas na matriz de PVC, contribuindo para o aumento da resistência ao rasgo nestas blendas.

A Figura 6 apresenta os resultados de dureza Shore A do composto de PVC, das borrachas nitrílicas e das blendas obtidas com diferentes agentes de partição.

O composto de PVC apresentou dureza superior a NBR PC e NBR PP. Para as blendas observou-se que o aumento no teor de borracha nitrílica na composição das blendas diminui a dureza dos compostos, em comparação à dureza do composto de PVC, devido à baixa dureza da borracha nitrílica pura. Quanto à influência do tipo de agente de partição da borracha nitrílica, as blendas que utilizaram em sua composição NBR PP apresentaram valores de dureza superiores àqueles das blendas com NBR PC.

\section{Análise morfológica das blendas}

A Figura 7 apresenta as morfologias observadas por MEV das blendas PVC/NBR com teores de 10, 20 e 30\% em massa com diferentes agentes de partição. As setas nas micrografias indicam a presença da fase elastomérica.

Analisando as morfologias, verificou-se para as blendas PVC/NBR PC (Figura 7a, b, c) que as partículas do elastômero se encontram no formato esférico, com tamanhos reduzidos e dispersas na matriz de PVC. Observou-se que ao aumentar o teor de NBR nas blendas há uma tendência de aumento do tamanho de partícula, que pode estar relacionado com o fenômeno de coalescência de partículas. Para a blenda PVC/NBR PC (80/20) (Figura 7b) observou-se que a fase elastomérica se encontra aglomerada, o que pode influenciar na rigidez desta blenda, obtendo maior deformação na ruptura e menor módulo elástico que a blenda PVC/NBR PC (70/30) (Tabela 3).

As blendas PVC/NBR apresentaram morfologia de fase dispersa com formato esférico. Observou-se uma heterogeneidade na morfologia das partículas de NBR com o aumento desta fase, fato já esperado uma vez que a razão de viscosidades entre NBR PP e o composto de PVC se apresentou acima do limite teórico de 3,7. Uma possível explicação das mor- fologias observadas pode estar relacionada à maior tendência das partículas de elastômero coalescerem. Aumentando-se o teor de elastômero nas blendas convencionais pode-se observar que ocorre diminuição do tamanho de partícula da fase dispersa e melhor distribuição desta fase na matriz de PVC.

Comparando-se as morfologias das blendas com diferentes tipos de agente de partição, pode-se observar que este agente interfere de maneira significativa no tamanho e distribuição da fase elastomérica. Blendas com agente de partição de PVC apresentaram maior tamanho de partículas e pior dispersão, quando comparadas às blendas em que o agente de partição foi o $\mathrm{CaCO}_{3}$.

\section{Conclusões}

$\mathrm{O}$ agente de partição da borracha nitrílica exerce grande influência tanto no processo de obtenção quanto nas propriedades mecânicas das blendas PVC/NBR. A NBR particulada com PVC possui maior viscosidade comparada a NBR particulada com $\mathrm{CaCO}_{3}$, e esta característica influência no processamento das blendas gerando maior atrito entre as partículas de NBR e PVC e aumentando o torque de equilíbrio.

O comportamento térmico das blendas é pouco afetado pelo agente de partição.

Quanto às propriedades mecânicas, o melhor desempenho foi obtido para blendas PVC/NBR que utilizaram NBR particulada com PVC em suas composições, as quais apresentaram maior resistência mecânica notadamente pelo maior tensão na ruptura e módulo elástico destas blendas.

A morfologia das blendas também é bastante afetada pelo tipo de agente de partição da NBR. Blendas PVC/NBR que utilizaram NBR com agente de partição de PVC em suas composições apresentaram maior tamanho de partículas e pior dispersão, quando comparadas às blendas em que o agente de partição foi o $\mathrm{CaCO}_{3}$.

\section{Agradecimentos}

Os autores agradecem a Capes pelo apoio financeiro, à Dra. Márcia C. Branciforti pelo auxílio com a análise morfológica e a Braskem S.A. através do programa NEO PVC (Núcleo de Estudos Orientados do PVC).

\section{Referências Bibliográficas}

1. Paul, D. R. \& Newman, S. - "Polymers blends", Academic Press, New York, 1 (1978).

2. Passador F. R.; Pessan L. A. \& Rodolfo Jr A. - Pol.: Ciênc.Tecnol., 16, p.174 (2006).

3. Shen F.; Li H. \& Wu C. - J. Polym. Sci., Part B: Polym. Phys., 44, p.378 (2006).

4. Rodolfo Jr., A.; Nunes, L. R. \& Ormanji, W. - "Tecnologia do PVC'. Proeditores/Braskem, São Paulo (2006). 
5. Browmick, A. K.; Hall, M. M. \& Benarey, H. A. - "Rubber products manufacturing technology", Marcel Dekker Inc, New York (1997).

6. Li, J. X. \& Chan, C. M. - Polym., 42, p.6833 (2001).

7. Liu, Z. H.; Zhu, X.; Wu, L.; Li, W.; Qi, Z.; Choy, C. \& Wang, F. - Polym., 42, p.737 (2000).

8. Manoj, N. R. \& De, P. P. - Polym., 39, p.733 (1998).

9. Liu, Z. H.; Zhang, X. D.; Zhu, X. G.; Qi, Z. N.; Wang, F. S.; Li, R. K. Y. \& Choy, C. L. - Polym., 39, p.5027 (1998).

10. Wang, Q.; Zhang, X.; Liu, S.; Gui, H. \& Lai J. - Polym., 46, p.10614 (2005).

11. Sen, A. \& Mukherjee, G. S. - Polym., 34, p.2386 (1993).

12. Bretas, R. E. S. \& D'Avila, M. A. - "Reologia de Polímeros Fundidos”, EDUFSCAR, FAPESP, São Carlos (2000).
13. Schramn, G. - "A pratical approach to rheology and rheometry". Gebrueder Haake, Karlsruhe (1994).

14. Paul, D. R. \& Newman, S. - "Polymers blends", Academic Press, New York, 1 (1978).

15. Utracki, L. A. \& Shi, Z. H. - Polym. Eng. Sci., 32, p.1824 (1992).

16. Huang, J. C. - J. Appl. Polym. Sci., 89, p.1242 (2003).

17. Pruneda, F.; Suñol, J. J.; Andreu-Mateu, F. \& Colom, X. - J. Therm. Anal. Cal., 80, p.187 (2005).

18. Pielichowski, K. - J. Therm. Anal. Cal., 55, p.559 (1999).

19. Ismail, H.; Tan, S. \& Poh, B. T. - J. Elast. Plast., 33, p.251 (2001).

20. Mousa, A.; Ishiaku, U. S. \& Ishak, Z. A. M. - Polym. Bulletin, 53, p. 203 (2005). 